Check for updates

Cite this: RSC Adv., 2018, 8, 3989

\title{
Synthesis of boron nitride nanotubes using an oxygen and carbon dual-free precursor
}

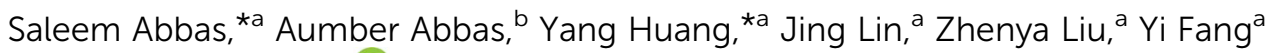 \\ and Chengchun Tang (D) *a
}

Boron nitride nanotubes (BNNTs) have attracted extensive research attention due to their intriguing properties and promising applications. However, the fundamental issue regarding the introduction of oxygen and carbon impurities into the final product remains a challenge. Herein, we utilized a novel precursor consisting of oxygen and carbon dual-free reactants $\left(\mathrm{MgF}_{2}, \mathrm{NH}_{4} \mathrm{Cl}\right.$, and $\left.\mathrm{B}\right)$ for the synthesis of pure BNNTs. The $\mathrm{MgCl}_{2}$ intermediate species of magnesium acts as a catalyst, which prevents the oxidization of the product and has been proved to be the key factor for pure BNNTs growth.

Received 23rd October 2017

Accepted 18th December 2017

DOI: 10.1039/c7ra11688h

rsc.li/rsc-advances since carbon is the first solid phase to appear upon cooling the vapors containing boron, nitrogen, and carbon. Tang et al. have developed the boric oxide CVD (BOCVD) approach, which is known as a significant progress in the growth of carbon-free BNNTs. ${ }^{27}$ Mixtures of the oxides of $\mathrm{B}, \mathrm{Mg}, \mathrm{Li}, \mathrm{Ga}$, and other metals are used as precursors in this approach. The precursors are activated at temperatures $>1300{ }^{\circ} \mathrm{C}$ by induction heating, and vapors of volatile $\mathrm{B}_{2} \mathrm{O}_{2}$ are generated. The $\mathrm{B}_{2} \mathrm{O}_{2}$ vapors are carried by Ar gas to interact with $\mathrm{NH}_{3}$ gas to generate BNNTs. ${ }^{27,28}$ Although carbon contamination can be effectively depressed, this approach requires a special vertically designed induction furnace having a high heating rate and large temperature gradient. The key problem with this approach is how to overcome the high equipment cost and prevent oxide contaminations, which are inevitably introduced due to the essentially used oxygen-containing precursors. Both carbon and oxygen are hard to be removed by post-synthesis treatment but can essentially influence the optical and electrical properties of BNNTs.

Herein, we report a simple methodology for the preparation of BNNTs using an inexpensive conventional horizontal tube furnace comprising an alumina ceramic tube chamber. We proposed a new route towards the synthesis of highly pure BNNTs based on a modified CVD method, namely the boron trifluoride CVD (BFCVD) method. As compared to the BOCVD method, we utilize oxygen and carbon dual-free reactants for the synthesis of BNNTs with high purity and high yield. The O-free reactants play a crucial role in the synthesis of BNNTs. The intermediates species of magnesium help with one dimensional growth which has been proved during the synthesis of one dimensional materials. ${ }^{29,30}$ The novel accessory in our approach is the $\mathrm{O}$-free precursor, especially $\mathrm{MgF}_{2}$ and its intermediate species $\left(\mathrm{MgCl}_{2}\right)$, which controls the formation of nanotubes, prevents oxidization, and may possibly improve chemical stability. The synthesized BNNTs have diameters in the range of
${ }^{a}$ School of Materials Science and Engineering, Hebei Key Laboratory of Boron Nitride Micro and Nano Materials, Hebei University of Technology, Tianjin 300130, P. R. China. E-mail: tangcc@hebut.edu.cn; huangyang@hebut.edu.cn; saleem_physics19@hotmail.com; Fax: +86-22-60202660; Tel: +86-22-60202660

${ }^{b}$ Chemical Engineering and Advanced Materials, School of Engineering, Newcastle University, Newcastle upon Tyne, NE1 TRU, UK 
25-45 $\mathrm{nm}$ with lengths up to several microns, displaying high aspect ratios. The optical property studies indicate that the wellstructured BNNTs show strong UV-emission centered at $335 \mathrm{~nm}$. The synthesis of BNNTs with a nano-size diameter and utilization of their promising properties present great potential for their application in high performance composites and optoelectronic nano-devices.

\section{Experimental}

\section{Synthesis of BNNTs}

High quality BNNTs have been synthesized by CVD reaction of boron (B) powder with $\mathrm{NH}_{3}$. In a typical procedure, powders of $\mathrm{B}, \mathrm{MgF}_{2}$ and $\mathrm{NH}_{4} \mathrm{Cl}$ were mixed in a ratio of $2: 2: 1$ and subjected to ball milling for 24 hours. The hybrid powder acquired from ball milling was employed in an alumina sample holder boat and placed in an alumina tube vacuum chamber by facing the open end of the tube opposite to the gas flow and the closed end was positioned at the center of the heating zone (Fig. 1). A nickel foil substrate was placed face down above the alumina boat containing the precursor, for the deposition and growth of BNNTs. After the ceramic alumina tube vacuum chamber was evacuated to $c a$. 30 mTorr, a pure $\mathrm{NH}_{3}$ gas flow was introduced into the chamber at the rate of $200 \mathrm{sccm}$. Subsequently, the reaction chamber was heated to $1350{ }^{\circ} \mathrm{C}$ for $4 \mathrm{~h}$. Vapors consisting of sublimated boron trifluoride $\left(\mathrm{BF}_{3}\right)$ were generated from the mixed powder of boron and $\mathrm{MgF}_{2}$ and reacted with $\mathrm{NH}_{3}$ gas to produce BNNTs. Detailed reactions are given in growth mechanism (will be discussed later). The covering of the boat is very crucial under these conditions for the reaction, as it prevents the vapors of boron species from escaping out before reacting with $\mathrm{NH}_{3}$ gas. After the reaction was carried out for $2 \mathrm{~h}$, the furnace was cooled down to room temperature naturally. All the toxic exhaust during the running of the experiment was absorbed by the $\mathrm{NaOH}$ solution cooling trap system. Finally, the pure white product was obtained from the nickel substrate.

\section{Characterization}

The surface morphology of the BNNTs was examined by high field scanning electron microscopy (HF-SEM, Hitachi SU-70). The microstructure of BNNTs was further investigated by bright field transmission electron microscopy (TEM) (JEOL, JEM-2100, Japan) and high-resolution transmission electron microscopy (HRTEM), combined with energy dispersive X-ray spectroscopy (EDX). Fourier transform infrared (FTIR) spectroscopy was carried out on a Nicolet 7100 spectrophotometer

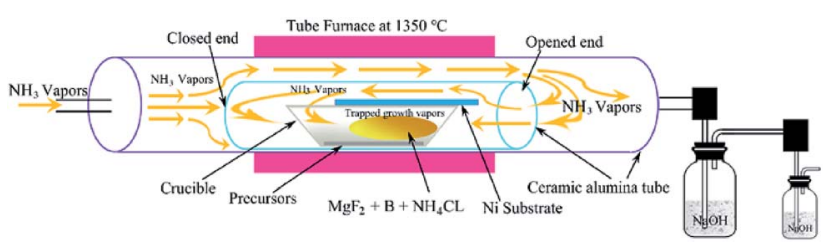

Fig. 1 Schematic of the apparatus, reaction conditions and CVD process for the synthesis of BNNTs. in the range of 400 to $4000 \mathrm{~cm}^{-1}$. Raman spectra were recorded on a Raman spectrometer using $532 \mathrm{~nm}$ excitation. The photoluminescence emission and excitation spectra were quantified using a Hitachi Fluorescence Spectrometer (F-7000).

\section{Results and discussion}

A representative SEM image is shown in Fig. 2(a), which displays the morphology of the as grown BNNTs. They consist of wirelike one-dimensional nanostructures. The absence of any distinguishable impurity phases, such as bulk BN sheets/flakes, confirms the pure phase composition of the product. The diameter distribution of the BNNTs was carefully measured. The diameters of BNNTs measured from the SEM image are in the range of 25-45 $\mathrm{nm}$, while the whole length reaches several microns, representing a high aspect ratios. The purity of BNNTs was further confirmed by EDX analysis. The EDX pattern in Fig. 2(b) shows the compositional analysis, mapping only boron and nitrogen atoms, indicating the high purity of the BNNTs. The copper and carbon signals come from the Holey carbon coated copper grid holding the specimen in TEM analysis. ${ }^{31-33}$ The absence of oxygen in the product indicates the strong capability of our method for the production of oxygen free BNNTs.

The microstructures and the inner morphology of the BNNTs were further investigated by TEM. Fig. 2(c) shows the low magnification TEM image of the BNNTs, showing the nanotubes crystallized as isolated tubules. The inset in Fig. 2(c) is the magnified image of a single nanotube clearly showing the high order cylindrical shape of the BNNTs. The magnified TEM image of a single nanotube maps an outer diameter of about $40 \mathrm{~nm}$ and an inner diameter of nearly $14.6 \mathrm{~nm}$. In addition, the diameters of the individual nanotubes measured from different positions were almost same, showing a uniform and ordered structure of the as grown product. The HRTEM image depicted in Fig. 2(d) demonstrates the parallel and straight walled structure of the tube. HRTEM analysis shows an evidently resolved interplaner distance of $0.34 \mathrm{~nm}$, which is the characteristic of the $d_{002}$ spacing of the hexagonal BN (h-BN) network, ${ }^{34}$ indicating the highly crystalline structure of BNNTs.

The selected area diffraction (SAED) patterns of the assynthesized BNNTs are presented in Fig. 2(e) and (f), showing the lattice parameters of the respective nanotubes, which further confirm their high crystallinity. Both near zig-zag and near arm-chair BNNTs were formed in our products. The SAED patterns (Fig. 2(e) and (f)) show the tube axis along the near zigzag and the near arm-chair configurations.

The structural and electronic properties of the as prepared BNNTs were studied using Raman and FTIR spectroscopy (Fig. 3). A single sharp Raman peak is noticed at about $1370 \mathrm{~cm}^{-1}$, which corresponds to a well-known $\mathrm{E}_{2 \mathrm{~g}}$ in-plane vibrational mode of the h-BN network (Fig. 3(a)). ${ }^{35,36}$ It is interesting to note that no other significant peaks (especially at around $1580 \mathrm{~cm}^{-1}$ belonging to carbon) ${ }^{37,38}$ are detected, which further confirms the high purity of the as grown BNNTs. The FTIR spectra in Fig. 3(b) shows three obviously distinguishable adsorption peaks at 802,1371 and $1516 \mathrm{~cm}^{-1}$. We correlate our 


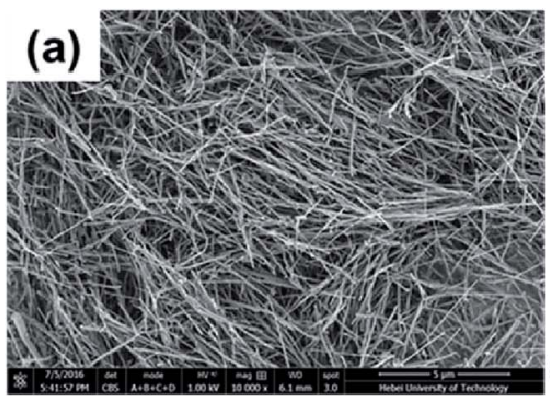

\section{(b)}
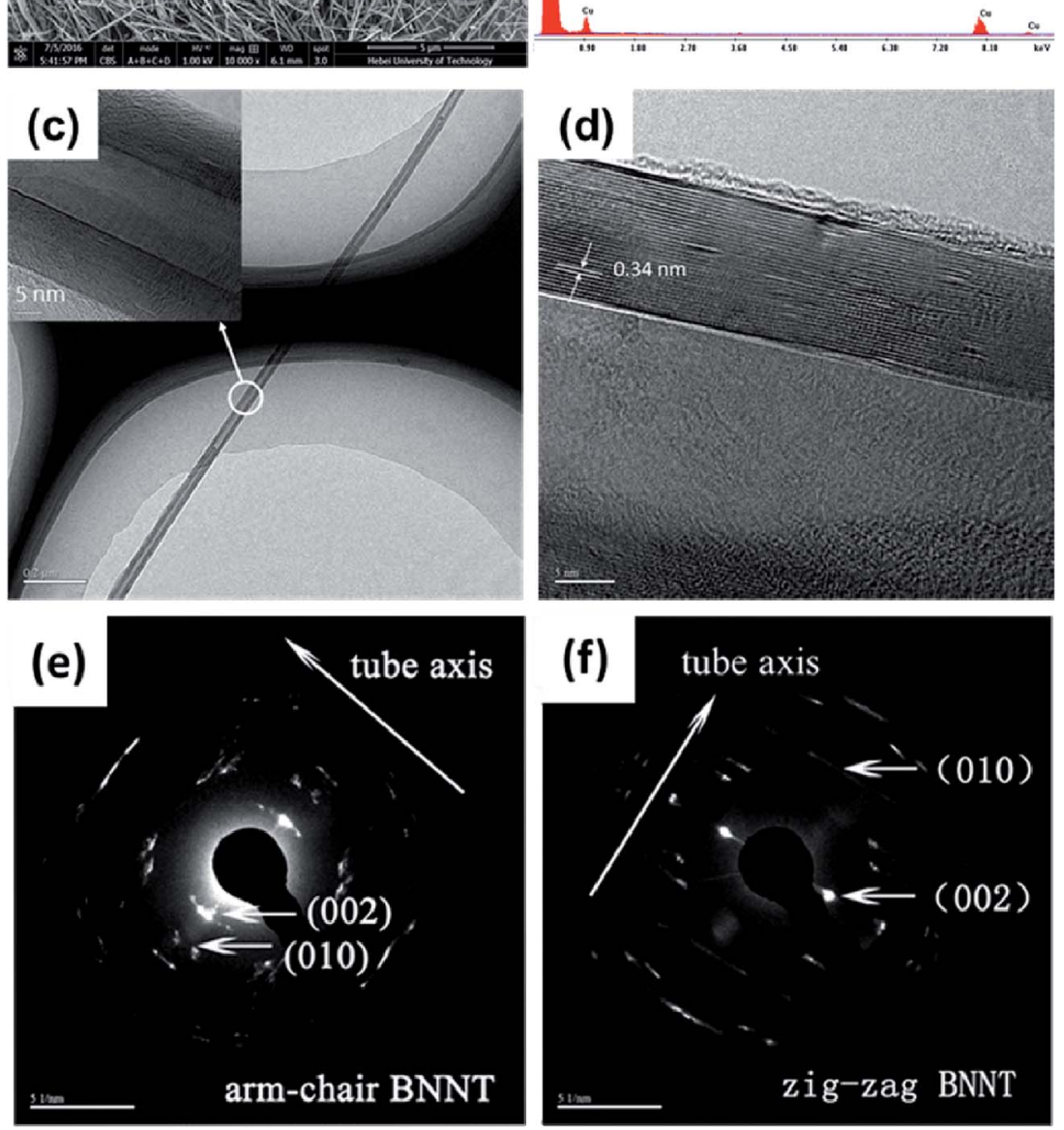

Fig. 2 (a) SEM image of the as-prepared BNNTs with uniform morphology, (b) EDX pattern displaying the high purity of BNNTs, (c) low magnification TEM image of a single BNNT and the corresponding high magnification image in the inset, (d) high resolution TEM (HRTEM) image of a typical BNNT clearly showing the layers of BN with an interplaner spacing of $0.34 \mathrm{~nm}$, (e) SAED patterns of near arm-chair, and (f) near zigzag BNNTs showing the lattice parameters of corresponding BNNTs.

FTIR spectrum with the $a b$ initio calculations that illustrate the IR active modes by the zone folding method. ${ }^{39,40}$ Although these theoretical studies correspond with single wall tubes, our experimental findings represent that the effect of the multiwall nanotubes on phonon frequency is negligible. The adsorption bands at 1371 and $1516 \mathrm{~cm}^{-1}$ can be assigned to the in-plane stretching vibrations of h-BN. This phenomenon has been well explained by the zone folding method, which assumes the tubes as seamless cylinder-shaped rolls of BN films. ${ }^{39}$ The sharp peak at $1371 \mathrm{~cm}^{-1}$ is attributed to the transverse optical mode of the BN films, which vibrates along the tube axis or the longitudinal direction of the BNNTs. ${ }^{41}$

The weak $1516 \mathrm{~cm}^{-1}$ band corresponds to the stretching vibration of the h-BN sheets along the tangential directions of
BNNTs. $^{16}$ This stretching vibration mode corresponds to a longitudinal optical mode of the h-BN that is Raman inactive. Interestingly, the longitudinal optical mode smoothens for the h-BN bulk material or thin sheets, and appears only when a strain is induced on the h-BN system by the tube curvature. Hence, we conclude that this longitudinal optical mode will be shown by highly crystalline BNNTs only, which is in good agreement with previous reports. ${ }^{16}$

The weak adsorption at $802 \mathrm{~cm}^{-1}$ is assigned to the out-ofplan radical buckling mode of the $\mathrm{BN}$ network, where $\mathrm{B}$ and $\mathrm{N}$ atoms move radically outward or inward. ${ }^{\mathbf{1 6 , 3 9}}$ Low energy electron diffraction (LEED) studies and computational analysis have demonstrated that the $\mathrm{B}-\mathrm{N}$ bonds in $\mathrm{sp}^{2}$ layered structures exhibit significant buckling., ${ }^{2,42}$ Displacement of the $\mathrm{N}$ atoms in 

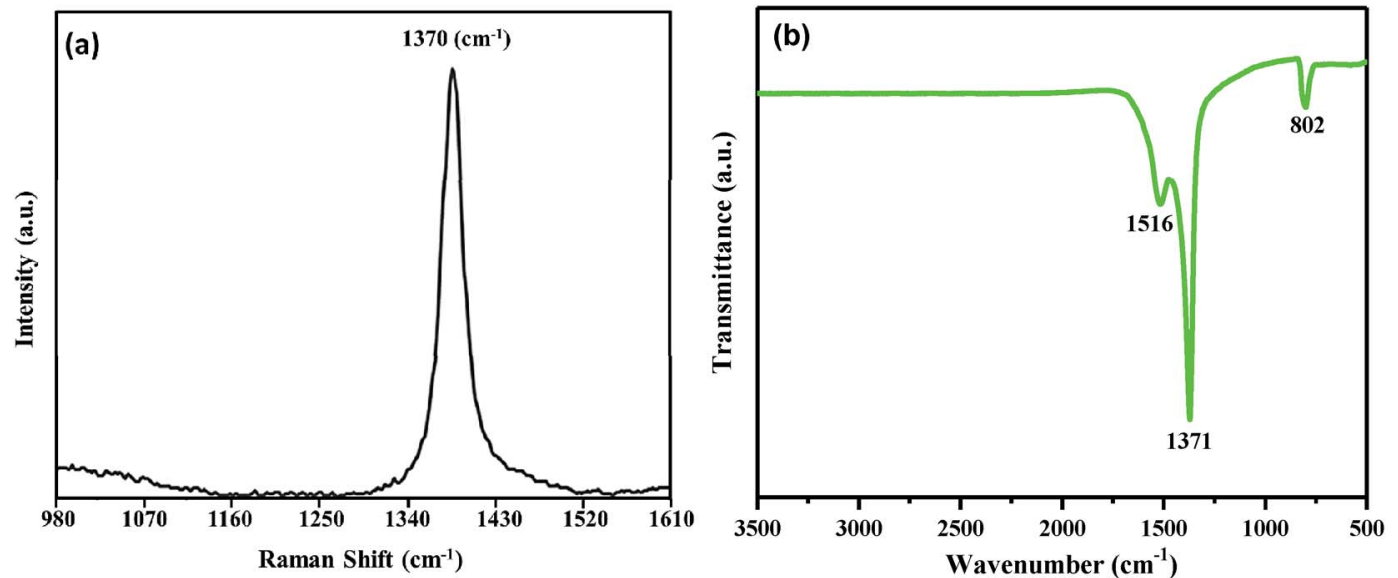

Fig. 3 (a) Raman spectroscopy of BNNTs showing a single strong peak at $1370 \mathrm{~cm}^{-1}$ corresponding to the $\mathrm{E}_{2 \mathrm{~g}}$ in-plane vibrational mode of BN, (b) FTIR spectroscopy of BNNTs displaying two peaks at $1371 \mathrm{~cm}^{-1}$ and $1516 \mathrm{~cm}^{-1}$ relating to the in-plane stretching mode, and third peak at $802 \mathrm{~cm}^{-1}$ attributed to the out-of-plane radical buckling mode of the BN network.

the outward direction has been theoretically proposed and experimentally witnessed. This buckling becomes more obvious due to the curvature of BNNTs. Some $\mathrm{sp}^{3}$ admixture takes place in $\mathrm{sp}^{2} \mathrm{BN}$ bonding as a result of this buckling structure, so that the softening of the FTIR vibrational modes can be perceived. Indeed, the $\mathrm{B}-\mathrm{N}$ stretching vibrations perpendicular to the axis of the BNNTs show a shift in wavenumber by $9 \mathrm{~cm}^{-1}$ (from 811 to $802 \mathrm{~cm}^{-1}$ ) as compared to bulk h-BN, showing the buckled structure of BNNTs with strains induced on the cylindrical BN network.

Based on our experimental success, a mechanism for BNNTs growth is suggested. We present the reactions taking place during the synthesis of BNNTs based on our chemical thermodynamic calculations carried out with the help of FactSage 7.1 software. Four steps are proposed for the synthesis of BNNTs:

1. When the blended powder consisting of $\mathrm{NH}_{4} \mathrm{Cl}, \mathrm{MgF}_{2}$ and $\mathrm{B}$ located in the alumina boat is heated in a tube furnace, $\mathrm{NH}_{4} \mathrm{Cl}$ dissociates into the vapors of $\mathrm{NH}_{3}$ and hydrogen chloride $(\mathrm{HCl})$ at the temperature above $520{ }^{\circ} \mathrm{C}$ (the boiling point of $\mathrm{NH}_{4} \mathrm{Cl}$ ) along with the reaction:

$$
\mathrm{NH}_{4} \mathrm{Cl}(\mathrm{s}) \rightarrow \mathrm{NH}_{3}(\mathrm{~g})+\mathrm{HCl}(\mathrm{g})
$$

The mixed vapors are prevented from escaping by the covering on the boat.

2. At sufficient vapor pressure, $\mathrm{HCl}$ vapors react with the $\mathrm{MgF}_{2}$ powder at high temperature to form $\mathrm{MgCl}_{2}$, and hydrogen fluoride (HF) vapors are generated as follows:

$$
2 \mathrm{HCl}(\mathrm{g})+\mathrm{MgF}_{2}(\mathrm{~s}) \rightarrow \mathrm{MgCl}_{2}(\mathrm{~g})+2 \mathrm{HF}(\mathrm{g})
$$

The produced intermediate species of magnesium, i.e. $\mathrm{MgCl}_{2}$, acts as a catalyst and plays a vital role during the growth process. Atomic collisions may take place to form small sized clusters of $\mathrm{MgCl}_{2}$. The formation of sufficient $\mathrm{MgCl}_{2}$ clusters maybe important, since a significant amount of the catalyst will be needed for achieving the required vapor pressure.

3. As HF vapors are very reactive, they react with boron powder to form $\mathrm{BF}_{3}$, which quickly starts vaporizing due to an elevated temperature.

$$
6 \mathrm{HF}(\mathrm{g})+2 \mathrm{~B}(\mathrm{~s}) \rightarrow 2 \mathrm{BF}_{3}(\mathrm{~g})+3 \mathrm{H}_{2}(\mathrm{~g})
$$

4. Upon reaching significant vapor pressure, the vapors consisting of $\mathrm{BF}_{3}$ start reacting with the active sites on the surface of the catalyst species. This dissolution of boron species in the catalyst species takes place in the presence of $\mathrm{NH}_{3}$, causing supersaturation and leading to the precipitation of the BNNTs along with the reaction:

$$
\mathrm{BF}_{3}(\mathrm{~g})+\mathrm{NH}_{3}(\mathrm{~g}) \rightarrow \mathrm{BN}(\mathrm{s})+3 \mathrm{HF}(\mathrm{g})
$$

Melted particles of the catalyst are condensed on the nickel substrate when their partial vapor pressure is sufficient. Then the BN species diffuse into the condensed catalyst leading to supersaturation and subsequent precipitation of BNNTs. The incorporation of $\mathrm{NH}_{3}$ gas further enhances the growth process. The BNNTs are transported and deposited on the Ni substrate placed over the alumina boat. Finally, well defined BNNTs with diameter around $25-45 \mathrm{~nm}$ and length up to several microns are collected. We didn't find BNNTs at temperatures lower than $1350{ }^{\circ} \mathrm{C}$. When the temperature is lowered to $1300{ }^{\circ} \mathrm{C}$, the generation of $\mathrm{BF}_{3}$ vapors could still be realized but at a decreased rate. BNNTS couldn't be generated due to the insufficiency of $\mathrm{BF}_{3}$ vapors. Thus, we suggest that $1350^{\circ} \mathrm{C}$ is the optimum temperature for the successful growth of BNNTs.

Our thermodynamic calculations indicate that vapors of $\mathrm{MgCl}_{2}$ and $\mathrm{BF}_{3}$ could exist at high vapor pressure. At reaction temperature, the vapors of $\mathrm{MgCl}_{2}, \mathrm{BF}_{3}$ and $\mathrm{NH}_{3}$ are essential for the growth of BNNTs. Thus, we believe that $\mathrm{MgCl}_{2}$, produced as an intermediate specie, serves as a catalyst during the growth 
process and is vaporized and removed at the end of reaction, as reported previously. ${ }^{29}$ In addition, the use of $\mathrm{MgF}_{2}$ is very important for the controlled release of $\mathrm{MgCl}_{2}$ vapors, and to control the vapor pressure of $\mathrm{BF}_{3}$ and $\mathrm{MgCl}_{2}$. If the vapor pressure is too high, the catalyst will easily grow up, leading to the failure of the growth of nanotubes. We did not find $\mathrm{MgCl}_{2}$ catalyst particles under electron microscopy because our synthesis temperature was very high $\left(1350^{\circ} \mathrm{C}\right)$, at which $\mathrm{Mg}$ and $\mathrm{Cl}$ couldn't survive ${ }^{15}$ and were evaporated. That is exactly why they were not detected in the TEM analysis. This is in good agreement with previous reports. ${ }^{15,29,43}$

The successful preparation of our highly crystalline BNNTs is based on the theory of nucleation. ${ }^{44,45}$ The probability of nucleation is given by following equation:

$$
P_{\mathrm{N}}=A \exp \left(-\pi \sigma^{2} / k^{2} T^{2} \ln \alpha\right)
$$

where $A$ is a constant, $\sigma$ is the surface energy, $k$ denotes the Boltzmann constant, $T$ stands for temperature in kelvin, and $\alpha$ represents the supersaturation, where $\alpha=P / P_{0} ; P$ is the vapor pressure of the growth species, and $P_{0}$ is the equilibrium vapor pressure of the condensed phase. It means, by assuming a constant surface energy at constant growth condition and $T$, it is possible to improve $\alpha$ and the probability of nucleation for both the catalyst particles and BNNTs by trapping the reactive vapor pressure to a critical level. In this study, surface energy corresponds to the catalyst particles that induce the fabrication of BNNTs. The partial pressure of the growth species and the size of the catalyst particles are responsible for the formation of BNNTs. We suggest that these particles are within the range of nanometers and enable the production of BNNTs. The condensation of droplets with a larger size could also take place, however these big particles did not result in BNNTs with large diameters because they required more $\mathrm{BN}$ growth species for supersaturation.

In a chain of experiments with different amounts of precursor powders, it is proved that higher vapor pressures enhance the yield of BNNTs. It is worthy to note that the yield of BNNTs also increases when the combustion boat is porous from one side, or partially covered by the substrate. The little closed end alumina tube reactor and the substrate placed over the combustion boat help with the accumulation and trapping of growth vapors which react with $\mathrm{NH}_{3}$, resulting in the improved nucleation rate for BNNTs. Besides, the small alumina tube is placed in a large alumina tube with the open end facing opposite to the flow of $\mathrm{NH}_{3}$. Such a design prevents the direct contact of $\mathrm{NH}_{3}$ flow with the reaction zone and hinders the growth vapors from being carried out with gas before reaching the critical vapor pressure for effective nucleation of BNNTs. $\mathrm{NH}_{3}$ gas can easily diffuse from the open end of the tube into the reaction zone for the nucleation and growth of BNNTs.

BNNTs show distinctive luminescence properties based on their particular nanoscale structure. Fig. 4 shows the optical emission and excitation spectrum of BNNTs. Generally, the possibility of a substance to show luminescence relies on its intrinsic band edge structure and other intrinsic or extrinsic defects. ${ }^{46,47}$ The intense UV emission band recorded at around

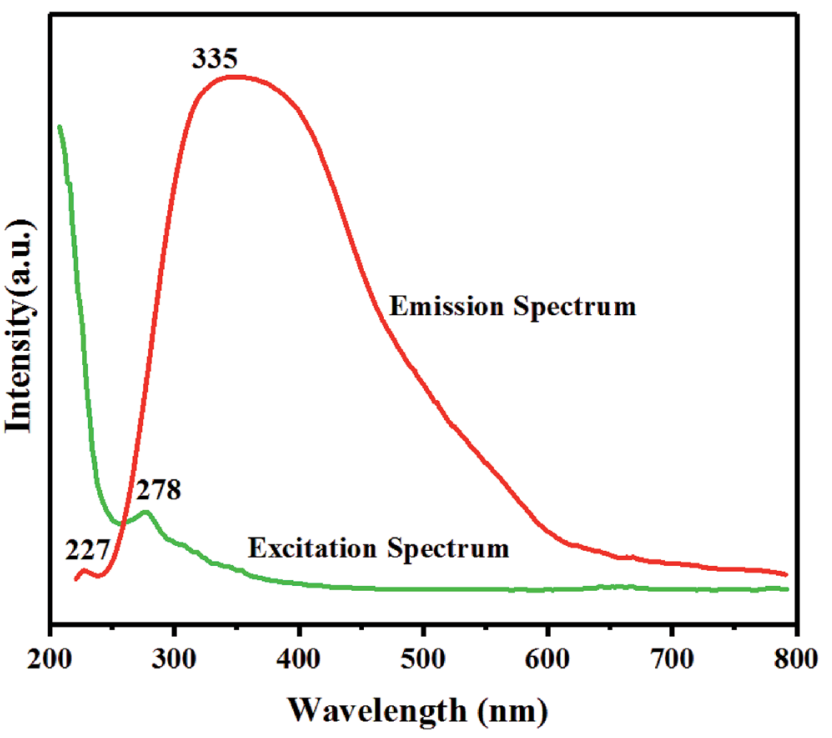

Fig. 4 Optical emission and excitation spectra of BNNTs.

$330 \mathrm{~nm}$ has been described frequently for the bulk h-BN sheets and numerous nanostructures of $\mathrm{BN}^{6,47-51}$ Therefore, the emission spectrum in Fig. 4 recorded at $335 \mathrm{~nm}$ comes from the nanotubes. This strong emission has been assigned to the defect associated sites (B or $\mathrm{N}$ vacancy defects) or intrinsic impurities in the BN network.

Relatively, a small emission peak recorded at $c a .227 \mathrm{~nm}$ could be analogous to the near-band-edge (NBE) exciton-related recombination in h-BN nanostructures. ${ }^{28}$ As illustrated previously, the purity and crystallinity of BN structures are the deciding factors for this emission band. ${ }^{52} \mathrm{~A}$ strong UV emission has been observed in highly crystalline h-BN nanostructures, for example, pure h-BN films or sheets ${ }^{53}$ and BN microtubes with good quality. ${ }^{52}$ However, this NBE emission could be perceived in most of the $\mathrm{BN}$ structures (e.g. nanoribbons, ${ }^{50}$ BOCVDBNNTs, ${ }^{6}$ bamboo shaped nanotubes ${ }^{54}$ only at a very low temperature (100 or $4.2 \mathrm{~K}$ ) and would disappear at room temperature. A deep UV-emission peak at $230 \mathrm{~nm}$ has only been reported for highly crystalline ultrafine BNNTs at room temperature. ${ }^{28}$ In this study, the NBE emission band observed at room temperature points out the reduced number of defects and, in turn, the high purity and crystallinity of our BNNTs relative to the other reported multi-walled nanotubes. These results imply that the as fabricated BNNTs have high crystallinity and demonstrate significant optoelectronic properties, which is critically important for their potential optoelectronic applications, especially in UV-range devices.

\section{Conclusion}

In summary, we presented an effective and facile strategy for the synthesis of BNNTs, via a novel precursor material. Pure and uniform BNNTs were obtained. For the first time, oxygen and carbon dual-free reactants were utilized for the fabrication of high quality BNNTs. The intermediate species $\left(\mathrm{MgCl}_{2}\right)$ from 
$\mathrm{MgF}_{2}$ serves as a catalyst and plays a key role in the synthesis of BNNTs. The as-prepared BNNTs show strong UV-emission properties. The synthesis of BNNTs with uniform size distribution and high UV-emission show great potential for their application in composites and high performance optoelectronic devices. We strongly believe that this work will open the path towards next generation optoelectronic nanodevices.

\section{Conflicts of interest}

There are no conflicts to declare.

\section{Acknowledgements}

The authors gratefully acknowledge the financial support from the National Natural Science Foundation of China (51402086, 51372066, 51572068, 51772075), the Natural Science Foundation of Hebei Province (E2016202122, B2015202079), the Program for Changjiang Scholars and Innovative Research Team in University (PCSIRT: IRT13060), the Hundred Talent Program of Hebei Province (E2014100011), and the Innovation Fund for Excellent Graduate Student of Hebei Province (No. 220056).

\section{Notes and references}

1 A. Rubio, J. L. Corkill and M. L. Cohen, Phys. Rev. B: Condens. Matter Mater. Phys., 1994, 49, 5081-5084.

2 X. Blase, A. Rubio, S. G. Louie and M. L. Cohen, Europhys. Lett., 1994, 28, 335.

3 N. G. Chopra and A. Zettl, Solid State Commun., 1998, 105, 297-300.

4 Y. Xiao, X. H. Yan, J. X. Cao, J. W. Ding, Y. L. Mao and J. Xiang, Phys. Rev. B: Condens. Matter Mater. Phys., 2004, 69, 205415.

5 D. Golberg, Y. Bando, K. Kurashima and T. Sato, Scr. Mater., 2001, 44, 1561-1565.

6 C. Zhi, Y. Bando, C. Tang, D. Golberg, R. Xie and T. Sekigushi, Appl. Phys. Lett., 2005, 86, 213110.

7 X. Chen, P. Wu, M. Rousseas, D. Okawa, Z. Gartner, A. Zettl and C. R. Bertozzi, J. Am. Chem. Soc., 2009, 131, 890.

8 C. Zhi, Y. Bando, C. Tang, R. Xie, T. Sekiguchi and D. Golberg, J. Am. Chem. Soc., 2005, 127, 15996-15997.

9 W. Wang, Y. Bando, C. Zhi, W. Fu, E. Wang and D. Golberg, J. Am. Chem. Soc., 2008, 130, 8144-8145.

10 A. Siria, P. Poncharal, A.-L. Biance, R. Fulcrand, X. Blase, S. T. Purcell and L. Bocquet, Nature, 2013, 494, 455-458.

11 C. H. Lee, D. Zhang and Y. K. Yap, J. Phys. Chem. C, 2011, 116, 1798-1804.

12 G. Ciofani, V. Raffa, A. Menciassi and A. Cuschieri, Biotechnol. Bioeng., 2008, 101, 850-858.

13 X. Li, X. Wang, J. Zhang, N. Hanagata, X. Wang, Q. Weng, A. Ito, Y. Bando and D. Golberg, Nat. Commun., 2017, 8, 13936.

14 M. Emanet, Ö. Şen and M. Çulha, Nanomedicine, 2017, 12, 797-810.
15 C. Tang, Y. Bando, G. Shen, C. Zhi and D. Golberg, Nanotechnology, 2006, 17, 5882.

16 L. Wang, T. Li, X. Long, X. Wang, Y. Xu and Y. Yao, Nanoscale, 2017, 9, 1816-1819.

17 Y. Chen, J. F. Gerald, J. S. Williams and S. Bulcock, Chem. Phys. Lett., 1999, 299, 260-264.

18 Y. Li, K. Zhao, S. Tung and E. Schneider, Mater. Lett., 2009, 63, 1733-1736.

19 D. P. Yu, X. S. Sun, C. S. Lee, I. Bello, S. T. Lee, H. D. Gu, K. M. Leung, G. W. Zhou, Z. F. Dong and Z. Zhang, Appl. Phys. Lett., 1998, 72, 1966-1968.

20 L. Han and P. Krstić, Nanotechnology, 2017, 28, 07LT01.

21 C. M. Lee, S. I. Choi, S. S. Choi and S. H. Hong, Curr. Appl. Phys., 2006, 6, 166-170.

22 A. Loiseau, F. Willaime, N. Demoncy, G. Hug and H. Pascard, Phys. Rev. Lett., 1996, 76, 4737.

23 L. Lu Hua, C. Ying and M. G. Alexey, Nanotechnology, 2010, 21, 105601.

24 L. H. Li, Y. Chen and A. M. Glushenkov, J. Mater. Chem., 2010, 20, 9679-9683.

25 D. Golberg, Y. Bando, Y. Huang, T. Terao, M. Mitome, C. Tang and C. Zhi, ACS Nano, 2010, 4, 2979-2993.

26 C.-Y. Su, W.-Y. Chu, Z.-Y. Juang, K.-F. Chen, B.-M. Cheng, F.-R. Chen, K.-C. Leou and C.-H. Tsai, J. Phys. Chem. C, 2009, 113, 14732-14738.

27 C. Tang, Y. Bando and D. Golberg, J. Solid State Chem., 2004, 177, 2670-2674.

28 Y. Huang, J. Lin, C. Tang, Y. Bando, C. Zhi, T. Zhai, B. Dierre, T. Sekiguchi and D. Golberg, Nanotechnology, 2011, 22, 145602.

29 C. Tang, Y. Bando, T. Sato and K. Kurashima, Chem. Commun., 2002, 1290-1291.

30 S. Abbas, Y. Huang, J. Lin, A. Abbas, X. Xu, J. Li, S. Wang, X. Jin and C. Tang, RSC Adv., 2016, 6, 29818-29822.

31 J. Li, H. Zeng, S. Sun, J. P. Liu and Z. L. Wang, J. Phys. Chem. $B, 2004,108,14005-14008$.

32 U. Mathis, R. Kaegi, M. Mohr and R. Zenobi, Atmos. Environ., 2004, 38, 4347-4355.

33 K. N. Yun, Y. Sun, J. S. Han, Y.-H. Song and C. J. Lee, ACS Appl. Mater. Interfaces, 2017, 9, 1562-1568.

34 D. Golberg, Y. Bando, C. C. Tang and C. Y. Zhi, Adv. Mater., 2007, 19, 2413-2432.

35 X. Li, M. B. Jordan, T. Ayari, S. Sundaram, Y. El Gmili, S. Alam, M. Alam, G. Patriarche, P. L. Voss and J. P. Salvestrini, Sci. Rep., 2017, 7, 786.

36 X. Chen, C. M. Dmuchowski, C. Park, C. C. Fay and C. Ke, Sci. Rep., 2017, 7, 11388.

37 V. Parashar, C. P. Durand, B. Hao, R. G. Amorim, R. Pandey, B. Tiwari, D. Zhang, Y. Liu, A.-P. Li and Y. K. Yap, Sci. Rep., 2015, 5, 12238.

38 V. K. Thakur, J. Yan, M.-F. Lin, C. Zhi, D. Golberg, Y. Bando, R. Sim and P. S. Lee, Polym. Chem., 2012, 3, 962-969.

39 L. Wirtz, A. Rubio, R. A. de La Concha and A. Loiseau, Phys. Rev. B: Condens. Matter Mater. Phys., 2003, 68, 045425.

40 L. Wirtz and A. Rubio, IEEE Trans. Nanotechnol., 2003, 2, 341-348. 
41 T. Chengchun, B. Yoshio, S. Guozhen, Z. Chunyi and G. Dmitri, Nanotechnology, 2006, 17, 5882.

42 S. H. Lim, J. Luo, W. Ji and J. Lin, Catal. Today, 2007, 120, 346-350.

43 C. Tang, Y. Bando, Y. Huang, S. Yue, C. Gu, F. Xu and D. Golberg, J. Am. Chem. Soc., 2005, 127, 6552-6553.

44 S. L. Mensah, V. K. Kayastha, I. N. Ivanov, D. B. Geohegan and Y. K. Yap, Appl. Phys. Lett., 2007, 90, 113108.

45 J. M. Blakely and K. A. Jackson, J. Chem. Phys., 1962, 37, 428430.

46 B. K. Gupta, V. Shanker, M. Arora and D. Haranath, Appl. Phys. Lett., 2009, 95, 073115.

47 P. Jaffrennou, J. Barjon, J. S. Lauret, A. Maguer, D. Golberg, B. Attal-Trétout, F. Ducastelle and A. Loiseau, Phys. Status Solidi B, 2007, 244, 4147-4151.

48 L. Museur, D. Anglos, J.-P. Petitet, J.-P. Michel and A. V. Kanaev, J. Lumin., 2007, 127, 595-600.
49 P. Jaffrennou, J. Barjon, T. Schmid, L. Museur, A. Kanaev, J. S. Lauret, C. Y. Zhi, C. Tang, Y. Bando and D. Golberg, Phys. Rev. B: Condens. Matter Mater. Phys., 2008, 77, 235422.

50 Z.-G. Chen, J. Zou, G. Liu, F. Li, Y. Wang, L. Wang, X.-L. Yuan, T. Sekiguchi, H.-M. Cheng and G. Q. Lu, ACS Nano, 2008, 2, 2183-2191.

51 P. Jaffrennou, J. Barjon, J. S. Lauret, B. Attal-Trétout, F. Ducastelle and A. Loiseau, J. Appl. Phys., 2007, 102, 116102.

52 Y. Huang, Y. Bando, C. Tang, C. Zhi, T. Terao, B. Dierre, T. Sekiguchi and D. Golberg, Nanotechnology, 2009, 20, 085705.

53 K. Watanabe, T. Taniguchi and H. Kanda, Nat. Mater., 2004, 3, 404-409.

54 P. Jaffrennou, F. Donatini, J. Barjon, J. S. Lauret, A. Maguer, B. Attal-Trétout, F. Ducastelle and A. Loiseau, Chem. Phys. Lett., 2007, 442, 372-375. 